\section{Oxford Studies in Metaethics}

Volume 6

Edited By

RUSS SHAFER-LANDAU

\section{OXFORD}

UNTVERSITY PRESS

\section{4}

\section{Desire-Based Theories of Reasons, Pleasure, and Welfare ${ }^{1}$}

\section{Chris Heathwood}

One of the most important disputes in the foundations of ethics concerns the source of practical reasons. On the desire-based or internalist view, only one's desires (broadly construed) provide one with reasons to act. ${ }^{2}$ On the value-based view, the strongest form of externalism about reasons, reasons are instead provided by the objective evaluative facts, and never by our desires. ${ }^{3}$ Lying in between, the hybrid or weak externalist view recognizes both sources. ${ }^{4}$ Similarly, there are desire-based and nondesire-based theories about two other phenomena: pleasure and welfare. It has been argued, and is natural to think, that holding a desire-based theory about either pleasure or welfare commits one to recognizing that desires do provide reasons for action-i.e. commits one to abandoning the

1 This chapter has benefited from the feedback of audiences at the University of Oxford, the Massachusetss Institute of Technology, the Tenth Conference of the International Society for Urilitarian Studies, and the University of Colorado at Boulder. Special thanks to Reid Blackman, Krister Bykvist, Tom Carson, Jamie Dreier, Jonas Olson, Jason Raibley, Michael Rubin, Russ Shafer-Landau, and two anonymous referees for Oxford University Press. Extra special thanks to David Sobel for extended discussion on these topics.

2 Defenders of this approach include Brandt (1979), Williams (1981), Smith (1994), and Schroeder (2007). Other labels for the broad approach include 'subjectivism' and 'the Humean theory'.

3 Defenders of this approach, also called "objectivism," include Quinn (1993), Dancy (2000), and Parfit (2001). In this camp I include those who maintain that it is the objective non-evaluative facts in virtue of which the objective evaluative facts hold that instead provide the reasons (see $\$ 2.2$ below).

${ }^{4}$ Chang (2004) advocates the hybrid theory. Scanlon (1998) and Raz (1999) write in the spirit of the value-based approach, but remain open to the possibility that desires provide reasons in "special, tather trivial cases" (Scanlon 1998; 48). According to Raz, "wants are very peculiar reasons" (1999: 62). 
value-based theory of reasons. ${ }^{5}$ The purpose of this chapter is to show that this is not so. All of the following can be true: pleasure and welfare provide reasons; pleasure and welfare are to be understood in terms of desire; desires never provide reasons, in the relevant way.

Another way to look at the part of this chapter that is about pleasure is as defending the value-based theory of reasons against a popular and interesting objection: the argument from matters of mere taste. ${ }^{6}$ This objection claims that the only plausible way to understand the reasons we have concerning decisions on matters of mere taste (e.g. which ice cream flavor to order) is by appealing to the idea that desires provide reasons.

These issues are important for several reasons. First, many are, like me, inherently interested in whether desires do provide reasons for action. If the desire-based theory of either pleasure or welfare - each a leading theory in its domain -implies that they do, we will want to know that. Second, there are interesting arguments both for the desire-based theories of pleasure and welfare.and for the value-based theory of reasons-but the former two seem in tension with the latter. Thus we have a sort of philosophical problem to resolve. Third, one kind of argument for the desire-based theory of reasons begins with the claim that desires provide reasons at least sometimes. ${ }^{7}$ Once this thin edge of the wedge works its way in, the unified thesis that only desires provide reasons for action will be more attractive. ${ }^{8}$ This argument is important because its conclusion, that only desires provide reasons, can be seen as a kind of threat to morality. If the thesis of this chapter is right, then two different ways to establish the first step of this argument-appeals to desire-based theories of either pleasure or welfare - can be resisted.

5 Sobel (2005) argues that the desire-based theory of pleasure undermines the valuebased theory of reasons. Scanlon (1998) argues against desire-based theories of welfare on the grounds that desires in fact don't provide reasons for action:

One thing that presumably makes desire theories of well-being plausible is the idea that if a person has a desire for something, then (other things being equal) he or she has reason to do what will promote that thing. But if what I have argued in Chapter 1 is correct, to do what will promote that thing. But if what I have argued in Chapter 1 is correct,
then having a desire for something hardly ever provides a person with a reason to promote it. (Scanlon 1998: 114)

This assumes what this chapter challenges: that these theories imply that desires provide reasons.

${ }^{6}$ Sobel (2005) may be the most explicit defense of this argument. Cf. the case of Ronnie and Bradley in Schroeder (2007). See also Goldman (2006: 472-3) and Scanlon (1998: 41-9).

E.g. Sobel (2005: 455-6) and Schroeder (2007: 2)

${ }^{8}$ For example, considerations of commensurability may lead one to hold that if desires sometimes provide reasons, then only desires provide reasons- that is, to prefer a pure desire-based approach over a hybrid theory.
I'll first discuss the pleasure case, and will aim to establish that one can endorse a desire-based theory of pleasure alongside a value-based theory of reasons. This won't, I should emphasize, involve denying that pleasure provides reasons. Then I'll discuss, though more briefly, the welfare case, and how one can endorse the desire-satisfaction theory of welfare while denying that desires provide reasons in the relevant way, again without denying that welfare is reason-providing.

Before doing either of these things, I'll introduce the desire-based and the value-based theories of reasons, and lay out some of the main arguments in their favor, arguments which will themselves play a role in the main argument of this chapter.

\section{THE DESIRE-BASED THEORY OF REASONS}

The dispute between desire-based and value-based theories of reasons is a dispute about normative reasons - reasons that justify, rather than merely explain, our actions and our attitudes. They are what make what we do or feel rational or reasonable. Motivating reasons, by contrast, merely explain rather than justify our actions. If I rell you that an exasperated parent hit his child for spilling her milk, I have just given you his motivating reason for doing that-what motivated him was the fact that she spilt her milk. ${ }^{9}$ And I have also explained why he did what he did. But I haven't thereby justified his behavior. If I tell you that your father has good reason to stop taking his arthritis medication, I am talking about a normative reason-something that would justify his stopping the medication. But I haven't thereby explained any behavior of his. He may never in fact stop taking the medication, despite the reason he has to do so.

As many philosophers have noted, it is hard to give a helpful definition of 'normative reason'. ${ }^{10}$ One of the most common ways to try to explain what it is for there to be a normative reason to do something or have some attitude is for there to be a consideration that counts in favor of doing it or having it. This is really just another way of saying that there is something that justifies doing it.

9 Or one might prefer to say that what motivated him was his belief that she spilt her milk, especially because the belief might be false, in which case there is motivation going on but no suitable fact to do the motivating. Parfit (1997:114 n. 28) suggests that we need not choose between these two conceptions of motivating reasons; both kinds of motivating reason exist.

Although $\S 1.3$ below mentions one non-theory-neutral proposal. 
According to the desire-based theory of reasons, anytime a person has a normative reason to do something, this is provided by some desire that the person either has, or would have, if he were-starting from his actual desires-to become idealized in some way, such as by being relevantly informed about each of his options, by vividly imagining and appreciating what it would be like for them to come about, or by undergoing what Richard Brandt calls "cognitive psychotherapy."

Bernard Williams, a leading proponent of the desire-based approach to reasons, characterizes the process of idealization as the process of "deliberating rationally." To deliberate rationally is to deliberate in light of all the relevant facts, in vivid appreciation of what each of one's options would be like, and in conformance with certain modest, merely "procedural" rules of rationality, such as the rule that instructs us to desire the most efficient means to our ends. On this terminology, the desire-based theory of reasons is the theory that anytime a person has a reason to do something, this is because doing it would satisfy a desire that the person would have after rational deliberation from his existing desires.

On the desire-based view, if I can either go for a walk or bake a cake, and, after rational deliberation, I wish to go for a walk, I thereby have a reason to go for a walk. If someone asks, Why did you go for a walk rather than bake a cake? - as in, What good reason was there for you to choose this way? the appropriate and literally correct answer, given the desire-based view, can be this: because, after thinking about it (in the right way), that's what $I$ wanted to do.

Aside from the fact that this is a fairly natural way to answer that question, why should we think that the desire-based theory is true? Here are four popular arguments. The first two are similar to each other, as are the last two.

\subsection{Argument 1: Explanation}

What may be the most prominent kind of argument in favor of the desire theory is one most associated with Williams. According to this argument, all reasons must be connected to one's desires because for something to bea reason in any sense, it must be at least potentially explanatory. Williams (1981: 102) writes,

${ }^{11}$ Brandt (1979: 11, 111-13). We could include further idealizations, as Williams does. We are here using "desire" very broadly, to mean any motivational state. This makes Williams' internalism the same as the desire-based theory, since I am calling anything in Williams' "subjective motivational set" a desire.
If there are reasons for action, it must be that people sometimes act for those reasons, and if they do, their reasons must figure in some correct explanation of their action.

But only the desire-based view delivers this. If a person can have a reason to do something no matter what she cares about and no matter what she could be made to care about (through rational deliberation from her existing cares), as is held by those who reject the desire-based view, then some normative reasons will fail to be even potentially explanatory. Thus, non-desire-based views must be mistaken.

\subsection{Argument 2: Motivation}

Relatedly, it seems true to many that if a person really does have a reason to do something, then it must be something he could be made to care about, something that could move him to act, at least if it were presented to him in the right way. It is just of the nature of reasons that they are the kind of thing such that if a person has one, it cannot leave him cold. Korsgaard (1986: 11) writes that

it seems to be a requirement on practical reasons, that they be capable of motivating us.

Again, only internalism can deliver this.

Sometimes the thought that it is of the nature of reasons that they be capable of motivating is presented as a basic intuition. But it can also be argued for by appeal to a relative of the principle that ought implies can. For it to be true that a person has a reason to do something, she must be able to do it; but to be able to do something, a person must be able to be motivated to do it. ${ }^{12}$

The motivation argument is slightly different from the explanation argument in that the previous one is making use of the idea that a defining role of reasons is to be available to explain action. This claim is different from the claim that it is of the nature of reasons that those to whom they apply must be able to be moved by them. Sometimes we are moved to do things we don't in fact do, due to some stronger, conflicting motivation. In such cases, a reason motivates a person without explaining any actual act. And even if they always did go together, the idea of being possibly moved by a reason and the idea of a reason being porentially explanatory are different ideas.

\footnotetext{
${ }^{12}$ See Darwall (1992: 166-8) and Huemer (2005: 158-9).
} 


\subsection{Argument 3: Content}

Williams suggests (1981: 109) another argument for the desire-based view:

What is it that one comes to believe when he comes to believe that there is reason for him to $\phi$, if it is not the proposition, or something that entails the proposition, that if he deliberated rationally, he would be motivated to act appropriately?

The suggestion is that the only intelligible content that can be given to a claim of the form, A has a reason to $\phi$, is that $A$ would desire to $\phi$ if he were idealized in some specified way-in other words, a content that can begiven to it by the desire-based view, but by no other view. Non-desire-based theories, the thought goes, will be unable to tell us what it even means to say that a person has a reason to do something, as even some advocates of these views admit:

If words like 'teason' and 'ought' neither refer to natural features, nor express our attitudes, what could they possibly mean? Non-reductive realists, as I have conceded, do nor give helpful answers to these questions. (Parfit 2006: 330)

\subsection{Argument 4: Reduction}

Even those who find externalism intuitive worry about there being these objective reasons, "set over against our subjectivity, as independent of it as the shapes and sizes of things" (MCDowell 1998: 100). Since, this argument claims, rejecting an internalist theory requires one to adopt a queer metaphysic and epistemology, the internalist theory must be true. Why should externalism require one to adopt a queer metaphysic and epistemology? One idea is that only the internalist theory allows for a plausible naturalistic reduction of the normative, thereby avoiding a metaphysic of irreducible normative facts, and its attendant problems. ${ }^{13}$ This is because the normative force that we are aware of when we are responding to reasons can, perhaps, arguably be reduced to the motivating force of the desires that motivate us to act when we act on reasons. No analogous reduction of forces to forces is available for externalist theories. As Darwall (1992: 168) writes,

For the philosophical naturalist, concerned to place normativity within the natural order, there is nothing plausible for normative force to be other than motivational force..... ${ }^{14}$

13 Such as problems concerning epistemic access, explanatory idleness (Harman 1977: chs. 1-2), and supervenience (Mackie 1977: 41; Dreier 1992).

4 Darwall adds
Let me spell out in more detail why a desire-based theory of reasons seems more conducive to a naturalistic reduction of reasons than does a value-based theory of reasons. Initially, this claim might seem puzzling. Both the desire-based theory and the value-based theory agree that normative facts at least depend on natural facts. Each agrees that anytime a person has a reason to do something, the fact that she has this reason holds, ultimately, in virtue of some natural fact or facts. They simply disagree about which natural facts are the ones in virtue of which people have reasons. Desire-based theorists maintain that the relevant natural facts are facts about the person's desires. Value-based theorists maintain that they are facts about objective value; but, like anyone; they will hold that these facts about objective value obtain in virtue of some natural facts. Thus, even for the value-based theorist, the ultimate ground of a reason is a natural fact. If desire-based theorists can reduce facts about reasons to the natural facts on which they believe these reasons depend, why can't value-based theorists reduce facts about reasons to the natural facts on which they believe these reasons ultimately depend? ${ }^{15}$

The answer is that the latter kind of reduction, although coherent, is less plausible. For normativity is a kind of force. Inherent to it is a kind of pull, or "oomph." If a person ought to do something, or has a reason to do something, this fact does not seem simply to be an inert fact about the world, alongside such facts as that snow is white and that the earth is round. Rather, the fact is, as it were, a nudge to him to do the thing; in some sense, it tells him to do it. If we reduce reasons to desires, we do not lose this feature of normativity, or at least not so much. For desires are also a kind of force-a motivating force. They pull us to do things; metaphorically speaking again, they tell us to do things. ${ }^{16}$

...perhaps when the agent's deliberative thinking is maximally improved by natural knowledge.

See also Goldman (2006: 484):

the only naturalist game in town is the internalist's derivation of reasons from coherent concerns...

and Markovits (chapter 11, this volume)

Many internalists about reasons are motivated by naturalistic metaethical intuitions. They hope that equating facts about reasons with facts about our motivations will render such facts less metaphysically and epistemologically mysterious.

15 Value-based theorists who are also buck-passers about value (see $\$ 2.2$ below) eliminate the middleman and hold that facts about reasons depend directly on natural facts.

${ }_{16}$ Not all natural forces ate plausible reduction bases for reasons. One possible difference between such forces and the natural force of desire is suggested in the following passage by Peter Railton (1999: 320): 
Compare this to a naturalistic reduction of reasons that reduces them to objective features of the world external to the agent who has the reasons. Suppose, for example, that we are value-based theorists of reasons who hold that knowledge is good in itself. We believe that whenever a person could do something that would lead to an acquisition of knowledge, she thereby has a reason to do it. If we are also reductionists about reasons, we will say something like this: the fact that Bob has a reason to do a certain act just is the fact that that act will lead to an acquisition of knowledge. But this latter fact-the fact that some act would lead to an acquisition of knowledge-is just a stale, inert description of matters of fact. Unlike facts about desires, it has no oomph. This is why desire-based theories of reasons are more amenable to a naturalistic reduction of normativity than are value-based theories of reasons.

These last two arguments-the content argument and the reduction argument - seem related. Perhaps we can see how they are connected by combining them as follows. Premise: the desire-based theory, and only the desire-based theory, does these two desirable things: it allows for a semantic reduction of the normative (in that it allows us to provide a content for reasons claims), and it allows for a metaphysical reduction of the normative (in that it allows us to identify normative properties or facts with naturalistic ones). Conclusion: the desire-based theory is probably true.

The four arguments we have looked at converge on one crucial idea: in agents who have deliberated rationally, there is a necessary connection between present reasons and present motivations or desires. This will be important later on.

\section{THE VALUE-BASED THEORY OF REASONS}

According to the value-based theory of reasons, our desires never provide us with reasons to act. Whenever we have a reason to do something, this is grounded instead in the fact that our doing this thing would bring about something valuable, or would be worthwhile in itself (perhaps for us, perhaps

Our notion of normativity appears to combine, in a way difficult to understand but seemingly familiar from experience, elements of force and freedom. On the one hand, a normative claim is thought to have a kind of compelling authority; on the other hand, if our respecting it is to be an appropriate species of respect, it must not be coerced, automatic, or trivially guaranteed by definition.

Gravity exhibits the force element, but not the freedom element. Desires, by contrast, like normativity, intuitively exhibit both force and freedom: they tell us what to do without making us do it (at least apparently, setting aside difficuit issues of free will). I am grateful to David Sobel here. for another person, or perhaps not for anyone-just valuable or worthwhile simpliciter). For example, if $I$ have reason to save a child from drowning in a shallow pond, this is based not in the fact that I have certain desires of sympathies concerning the child (or would if I reflected on the matter aright), but instead in the fact that it would just be a good thing for this child not to die. I could have this reason even if I in fact had no sympathy, and cared nothing for this child's welfare, and could not be made to care.

Other than the fact that it sounds plausible enough to say that there is a good reason for me to save this child never mind my particular interests, why think that a value-based theory might be true?

\subsection{The Arbitrariness Argument}

Arguments for the value-based theory must be, at least in part, arguments against the idea that desires ever provide reasons. Perhaps the strongest such argument is the arbitrariness argument. According to those who reject the value-based view, it often happens that someone's reason for doing something is based, ultimately, in some desire of his. In other words, desires can provide reasons. But if some desire is the ultimate basis for some reason, then there can be no reason for having this desire. If there were, then the desire wouldn't be the ultimate basis for the reason. Whatever supplied the reason for having the desire would be more fundamental. But if there is no reason for having the desire, then the desire is arbitrary. Thus, anytime it is supposed to be that some desire is providing a reason, this reason is ultimately based in arbitrariness. But, the argument daims, it can't work that way. Arbitrariness is anathema to reasons. If a "reason" is based ultimately on an arbitrary state - a state we have no reason to be in -it can't be a real reason after all. Why should we follow the direction of some desire, when that desire is itself without any justification? How could such a desire have any legitimate authority?

Here is a way to illustrate the point. A says to $B$, "What reason is there for you to do $X$ ?" B replies, "Doing $X$ will lead to $Y$, and I want $Y$ to occur." $A$ inquires further, "Why do you want $Y$ to occur?" $B$ continues in the same vein: "Because $Y$ will lead to $Z$, and I want $Z$ to occur." A won't let it go: "What reason is there to want $Z$ to occur?" B's chain of desire must eventually stop of course, presumably in some intrinsic desire, or desire for something for its own sake rather than for what it leads to. Let's suppose that $B$ intrinsically desires that $Z$ occur. In response to A's question, "What reason is there to want $Z$ to occur?," B thus replies, "Well, $Z$ won't lead to anything else I want; I just want $Z$ to occur, for its own sake." But $A$ can reasonably ask, "Ok, but why? Why want $Z$ to occur for its own sake?" 
B might be inclined to say, "Because it would be a good thing for $Z$ to occur. That is the reason to want it to occur." But if this is going to be a genuine case of a desire-based reason, $B$ can't answer that way. $\bar{B}$ must instead say, "There is no reason to intrinsically want $\mathrm{Z}$ to occur, but, still, I do." Since what would be a desire-based reason must in this way have arbitrary foundations, and since true reasons can't have an arbitrary basis, there cannot be desire-based reasons. This point about arbitrariness may be what lies at the heart of Plato's Euthyphro problem.

With an illuminaring metaphor, Derek Parfit (2001: 24-5) makes more or less the arbitrariness argument

According to [desire-based theories], instrumental reasons get their force... from some intrinsic desire. And on such theories, as we have seen, we cannot have reasons to have such desires. So all reasons get their force from some desire that, on these theories, we have no reason to have. Our having such desires cannot itself, I am arguing, give us any reasons. If that is true, desire-based theories are built on sand. ${ }^{17}$

\subsection{The Value-Based Theory of Reasons and the Buck-Passing Account of Value}

The name "value-based theory of reasons" suggests that an essential feature of this theory is a reduction of reasons to value. This implies that the theory stands in opposition to the so-called buck-passing account of value, which attempts the opposite: to explain value in terms of reasons. But in fact this is no part of the theory (and for this reason this name is imperfect). What is essential to the theory being discussed here is that reasons are not to be explained subjectively, in terms of the attitudes of the person who has the reasons, but objectively, in terms of features other than the attitudes of the person who has the reasons. Buck-passers who bold that facts about reasons are grounded in objective natural facts rather than in subjective natural facts are advocates of the value-based theory of reasons.

Returning to the child drowning in the pond, many value-based theorists of reasons will hold that the bystander has a reason to save the child, whatever the bystander's desires or other subjective states. If this

17. Arguments along these lines are also defended by Dancy (2000:37 9), ShaferLandau (2003: 42-3), Huemer (2005: 50-2, 60-4), and Phillips (2007: 461). Smith, desire-based theorist, agrees that "arbitrariness is ... a featute of a consideration that tends to undermine any normative significance it might initially appear to have" (1994: 172-3) and attempts to show that his own internalist, but non-relativistic, theory of 172-3), and atrempts to show that his own inct believe that Smith's view does the trick casons a however. Even if all agents with pre-existing desires would converge through idealization on a single set of desires, we have no reason to have this set of desires over none at all. The set as a whole remains arbitrary. value-based theorist is not a buck-passer, and holds that value is more basic than reasons, she will say that the bystander's reason is grounded in an evaluative fact such as that it would be a good thing for this child to live. If, on the other hand, this value-based theorist is a buck-passer, and holds that reasons are more basic than value, she will say that the bystander's reason is grounded directly in a natural, non-evaluative fact such as that the child's life would be saved by the act. That some act is the saving of a life is just a reason to do the act, and this is just a basic fact about reasons. This is a value-based- or externalist-friendly claim because the natural fact that grounds the reason is not a subjective fact about the agent's desires but an objective fact about the world external to the agent.

Value-based theorists will agree that the reasons in this or any case are ultimately grounded in some natural facts about the case not having to do with the agent's desires. Buck-passers hold that these natural facts provide the reasons directly, while non-buck-passers hold that these natural facts directly ground evaluative facts, which, in turn, provide the reasons.

Value-based or externalist buck-passers do not run afoul of the arbitrariness argument. They avoid arbitrariness because, on their view, a person's reasons are not ultimately grounded in some desire that she has no reason to have. When $A$ asks $B$, "But why want $Z$ to occur for its own sake?," if $B$ is a buck-passing value-based theorist, $B$ can say, "I do have a reason to want $Z$ to occur for its own sake; for $Z$ is just inherently such that there is reason to want it to occur for its own sake."

\section{HOW ONE CAN BE A DESIRE-BASED \\ THEORIST OF PLEASURE AND A VALUE-BASED THEORIST OF REASONS}

\subsection{The Case of Matters of Mere Taste}

The best way to get the ptoblem this part of the chapter is about off the ground is to consider a kind of case that makes it very natural to think that at least some of our reasons are provided by our desires. This on its own would not establish the desire-based theory, but it would refute the value-based theory. The case in question concerns matters of mere taste. Suppose at the ice cream shop I can choose between chocolate and vanilla. I reflect in the ideal way, and it's clear that I'm in the mood for chocolate. That's the flavor I want. So that's the flavor I order, and enjoy. Suppose next that I am asked to justify my choice. Surely a thing to say to justify my choice is this: it was sensible for me to order the chocolate because that's the flavor I wanted. But if this natural thing to 
say is literally correct, then desires at least sometimes provide reasons. The value-based theory must therefore be mistaken. ${ }^{18}$

As just about everyone agrees, an implausible reply for the value-based theorist to make to the objection from matters of mere taste is to claim that the taste of chocolate is just an objectively better taste than the taste of vanilla, and that this is what provides the reason to choose the chocolate.

But a different reply is plausible. The value-based theorist can claim that I had reason to choose the chocolate not because I wanted it more, and not because the taste of chocolate is objectively better, but because I would enjoy the chocolate more once I got it, and this enjoyment is good in itself for me, and is therefore what justifies my choice. ${ }^{19}$ They can go on to explain why it is so natural to appeal to our desires when justifying our choices concerning matters of mere taste. It is because we desire pleasure, and have learned what is likely to give us pleasure; so we tend to prefer the option that will give us pleasure. Thus, while a desire for the chocolate is a reliable indicator of a reason to choose it, it is not what actually grounds the reason.

This plausible reply faces a problem, however, when we look further into the nature of the enjoyment that, according to it, is providing our reason.

\subsection{The Desire-Based Theory of Pleasure}

Our first thought as to the nature of pleasure or enjoyment--I will ignore any possible differences between the two here-might be that it is just a certain feeling or sensation, one with which we are all intimately acquainted, but the nature of which is simple and unanalyzable, perhaps like that of the sensation of red. So just as the best we can do to call our attention to the sensation of red is to cite its typical causes-ripe tomatoes, stop signs, etc. - the best we can do with the feeling of enjoyment is to identify it by means of its typical causes-basking in the sun, chugging a lemonade, working on a Sudoku puzzle, watching a drama unfold.

A problem with this distinctive-feeling view one kind of felt-quality theory is that phenomenological reflection seems to reveal that, unlike with the sensation of red and its causes, there is in fact no single, distinctive feeling caused by each of the four enjoyable activities listed above. ${ }^{20}$

18 For an excellent laying out and defense of this line of argument, see Sobel (2005). 19 See Sobel (2005) and Scanlon (1998: 42). Goldman (2006: 472-3) considers this sort of reply, but maintains that one has reason to experience such enjoyment only if one cares about experiencing such enjoyment-something value-based theorists are likely to reject.

20 This objection to the distinctive-feeling view, whose advocates include G. E. Moore (1903: §12), was raised by Sidgwick (1907: 127). I follow Carson (2000:
On the other version of the felt-quality theory-the bedonic tone theory - it is not that each of the experiences above causes a further experience (the feeling of pleasure), but that each of the experiences above, though intrinsically different in many ways, manages to have the additional intrinsic feature of being pleasurable. As an analogy, consider how sounds that are otherwise very different can each manage to have the feature of being loud, a feature intrinsic to the sounds. ${ }^{21}$

The main alternative to the felt-quality approach is the attitude-based approach, according to which what makes each of the aforementioned experiences enjoyable has nothing to do with any further feelings they cause, and nothing to do with anything intrinsic to the experiences, but instead with the attitude we take up towards the experiences. A natural attitude to appeal to here is our desire to be experiencing the experience as we are experiencing it. This, according to the desire-based theory of pleasure, is what makes the experience enjoyable. ${ }^{22}$

I believe the attitudinal approach to be more plausible. The cases that most clearly support it over the hedonic tone theory (the superior version of the felt-quality approach) involve sensations that some people like and others don't, and sensations that bother some people but not others. The sound of fingernails scratching on a chalkboard is extremely unpleasant to many people, but not at all unpleasant to others. If unpleasantness is intrinsic to unpleasant sensations, as is maintained by the hedonic tone theory, then one of these groups of people has to be mistaken. If this sound really is intrinsically unpleasant, then those whom it doesn't bother and who therefore judge it to be not at all unpleasant, are wrong. That is hard to swallow.

Another kind of case involves enjoyable sensations we grow tired of after prolonged exposure. Flowers and perfume initially smell nice, but can begin to nauseate after a while. One way this may happen is that the

13-14) in using "felt-quality theory" to cover the distinctive-feeling view (so-called by Feldman 2001: 663) and the hedonic tone theory.

21 This analogy is due to Kagan (1992). Defenders of the hedonic tone theory indude C. D. Broad (1930: 229-31), Katl Duncker (1941), and, most recendy, Aaron Smuts (forthcoming)

22 Some writers, e.g. Sumner (1996: 87-91), use the terms "internalism" and "externalism" to distinguish the two main kinds of theory of pleasure where I am using "feltquality theory" and "attitude-based theory." Defenders of a desire-based theory of pleasure include Spencer (1871: \$125), Brandr (1979: 38), Parfit (1984: 493), Carson (2000: 13), Scanlon (2002: 339), and myself (2007a). Defenders of non-desire-based attitude-based theoties include Sidgwick (1907:127), who appeals to the attitude of apprehending as desirable, Feldman (1988; 2004: 79-81), who appeals to propositional pleasure, and Hall (1989), who appeals to liking. In his forthooming book On What Matters, Parfit now endorses a liking-based theory 
sensation itself somehow transforms after prolonged exposure-you start getting a different smell. But surely another way this happens is that the smell stays the same while our attitude about it changes. What we once wanted to be experiencing, we now want not to be experiencing. What was once an enjoyable sensation no longer is. Since this is a case of change in the enjoyableness of the sensation without an intrinsic change in the sensation, hedonic tone theories, which hold that enjoyableness is intrinsic, cannot accommodate this. ${ }^{23}$

\subsection{The Value-Based Theorist's Response to the Case of Matters of Mere Taste, Given the Desire-Based Theory of Pleasure}

The most plausible initial response for the value-based theorist of reasons to make to the case of matters of mere taste is to agree that I do have more reason to choose chocolate, but to hold that this reason is provided not by my preference for chocolate but by the fact I would enjoy the chocolate more. This raised the question, What is enjoyment anyway? The most plausible answer to that question-no matter your view about reasons-is, I claimed, the desire-based theory of pleasure. But then the value-based theorist of reasons has a problem. For it then turns out that, in appealing to the enjoyment the chocolate would give as the source of the reasons to choose it, the value-based theorist of reasons is covertly appealing to desire. She is, in effect, evidently committing herself to the idea that desires do provide reasons after all. For the choice of chocolate to be the more enjoyable choice just is for it to be the choice that will lead to the gustatory experience I'll be more strongly desiring to be getting as I am getting it. That enjoyment contains desire as a component seems to undermine the value-based theorist's reply to the case of matters of mere taste. ${ }^{24}$

\subsection{Some Unpromising Strategies for the Value-Based Theorist of Reasons}

Recognizing this, the value-based theorist might be tempted, on these very grounds, to reject the desire-based theory of enjoyment. And she might do this without abandoning the attitudinal approach to pleasure. The brief discussion above showed at most only that an attitudinal theory of pleasure is more plausible than a felt-quality theory of pleasure. It said nothing in

\footnotetext{
${ }^{23}$ Some parts of this subsection are taken from my $2007 \mathrm{~b}$
} 24. See Sobel (2005: 444). support of the further claim that the desire-based theory of pleasure is the best attitudinal theory. This makes for a way out for the value-based theorist of reasons. She could claim that what makes an experience pleasurable is not the fact that the subject is desiring it but the fact that the subject is liking it, or taking pleasure in it. Liking and taking pleasure in are attitudes, and so accounts of pleasure based on them will enjoy the advantages of the attitudinal approach over the non-attitudinal approach, but liking and taking pleasure in are not the same thing as desiring, and so don't threaten the value-based theory of reasons in the way we have been discussing. ${ }^{25}$

But I don't think this tack is a promising one, for there is in fact reason to prefer a desire-based theory of pleasure over a "liking-based" theory of pleasure as the fundamental truth about the nature of pleasure. Liking, unlike desiring, entails belief, or awareness. That is to say, necessarily, if S likes that $p$, then $S$ believes that $p$; or if $S$ likes experience e, then $S$ is aware of $e$. This strongly suggests that liking is a non-basic, or composite, attitude, and that belief, or awareness, is one of its components. It therefore raises the question of what we need to add to mere belief or awareness to get likingi.e. of what liking's other components are. The most natural answer is desire. What follows is this: while it is true that the pleasurableness of a pleasurable experience is explainable in terms of the attitude of liking, this attitude is, in turn, explainable in terms of desire. Thus, the desire theory of pleasure, rather than the liking theory of pleasure, is the fundamental truth about pleasure. Whenever there is enjoyment that the value-based theorist wants to say is providing a reason, there will also be desire in the mix. ${ }^{26}$

Even if I am wrong that the attitudinal approach is superior, it's not clear that a felt-quality theory of pleasure will help the value-based theorist of reasons handle the case of matters of mere taste. This is because, if a feltquality theory of pleasure is true, then it becomes less plausible that pleasure itself actually provides reasons; but the whole point of the value-based theorist's original response to the case of matters of mere taste is that the pleasure the chocolate would provide is the source of the reason to choose it. On the felt-quality view of pleasure, pleasure is really just another sensation among others (or, on its hedonic tone variety, just another feature

${ }^{25}$ Parfit (forthcoming) essentially takes this strategy. Sobel (chapter 3, this volume) criticizes it.

${ }^{26}$ It is true that property F's entailing property $G$ (and not vice versa) doesn't guarantee that $F$ is a composite property with $G$ as a component. Being red entails being colored, but being red may still be a simple property. But when we know the case at hand is not a determinate/determinable case, as in the case of liking and belief/awareness, the entailment suggests the component idea. 
of sensations among others). Just as there is the taste of chocolate, the feeling of sun on your back, and the sound of Ella Fitzgerald's voice, there is the feeling of pleasure. On the felt-quality theory, it must be just a contingent fact about us humans that we tend to like and want this feeling of pleasure (just as it is contingent that we tend to like and want to hear the sound of Ella Fitzgerald's voice). Realizing this invites us to imagine creatures indifferent to this feeling (in the same way that you are probably indifferent to, say, the white color sensation you are experiencing while looking at this page). It is hard to see why such a creature could have any reason to experience pleasure, on this conception of pleasure. Of course, we can suppose that the sensation of pleasure is good in itself for anyone who experiences it, and if we do, it is plausible to maintain that it provides reasons. But given this conception of pleasure, it is hard to see why we would want to say that pleasure is good in itself for us in the first place (in the same way that it would be hard to see why we would want to say that the white color sensation you are experiencing while looking at this page is an intrinsically good sensation for us to experience). ${ }^{27}$

Moreover, if the value-based theorist is prepared to say that the feeling of pleasure, on the felt-quality view of pleasure, is reason-providing, why not just put forth this sort of view earlier in the dialectic, and say that the taste of chocolate itself provides more reason to choose it than does the taste of vanilla? The value-based theorist wouldn't do this, of course, because it is too hard to believe. But the move under discussion here teally isn't very different.

\subsection{How a Value-Based Theorist of Reasons Can Endorse Both Pleasure as a Source of Reasons and the Desire-Based Theory of Pleasure}

I believe that what provides the reason to choose chocolate in the case of matters of mere taste is the future enjoyment, and I hold that enjoyment is to be analyzed in terms of desire; therefore, I am committed to the idea that one's desires are sometimes at least involved in the reasons one has. Nevertheless, this is not enough to establish, in the relevant sense, the

27 Sobel (2005: 444-6) makes a similar argument. A certain version of the hedonic tone theory, the feels good theory, may avoid this argument. On the feels good theory, to be a pleasurable experience is to be one that has the intrinsic quality of feeling good. It is not unreasonable for the feels good theorist to insist that creatures who don't care about feelings that feel good nevertheless have a reason to feel them. After all, they feel good. Defenders of the feels good theory include Crisp (2006: 109) and Smuts (forthcoming). I believe that the feels good theory has other problems, however; see my $2007 \mathrm{~b}$. anti-value-based-theoretic claim that desires sometimes provide reasons. There are two ways this fails to be established:

i. First, when the desire-based theorist of reasons claims that one's desires provide one with reasons, what has to be meant is that one's present desires (or present idealized desires) provide one with reasons, but when the value-based theorist appeals to future enjoyment as providing a reason, the desire involved in this enjoyment is a future desire.

ii Second, when enjoyment provides reasons, desire is only a component of this reason-providing state. The reason-providing state is not itself a state of desire.

Since these two points are independent, it is overdetermined that the desire-based theory of pleasure does not commit one to the view that desires provide reasons. I will elaborate on each of these two key points in some detail, as they form the heart of the explanation of how one can be a value-based theorist of reasons and a desire-based theorist of pleasure.

\subsubsection{Why Desire-Based Theorists of Reasons Can't Appeal to Future Desires}

Derek Parfit also holds that pleasure grounds reasons, that it is reducible to desire, but that desires never ground reasons (Parfit 2001: 16, 26). ${ }^{28}$ Parfit resolves the apparent inconsistency here by appealing to the first of the two claims above-namely, that when the desire-based theorist claims that desires provide reasons, what is meant is that one's present desires provide one with reasons. He asks us to imagine

some smoker, who does not care about her further future, and whose indifference would survive informed deliberation. According to desire-based theories, this person has no reason to stop smoking. It is true that, if she later got lung cancer, she would then have many strong desires that her fatal illness would frustrate. But these predictable future desires do not, on desire-based theories, give her now any reason to stop smoking. If we appeal to such future desires, claiming that they give this person such a reason, we are appealing to a value-based theory. (Parfit 2001: 24)

However, Parfir doesn't explain why such an appeal is an appeal to a valuebased theory. David Sobel describes this as a "questionable terminological move" and concludes that "Parfit's seemingly exciting conclusion that desires never ground reasons is less exciting than it appears because of bis odd terminological choice" (Sobel 2005: 455). Sobel has in mind that

\footnotetext{
${ }^{28}$ Or at least he held this. He may now prefer (in Parfit forthcoming) to explain
} pleasure in terms of liking rather than desire. 
when desire-based theorists claim that desires provide reasons, they are entitled to include future desires as well, so that the reasons Parfit's smoke has now (which involve desires she now lacks but will have in the future) count as internal rather than external reasons.

Parfit is of course free to say that the theory he calls the "value-based theory of reasons" is meant to allow that future desires be involved in reasons-that such desires are properly considered external to the agent-and Sobel is free to say that the theory he associates with this expression is meant to disallow this. But whatever terms we use, I believe that there is still a real, not merely verbal, dispute here. To get a grip on it, we should look at the main sorts of considerations that have been used to support the two kinds of theory-the arguments that were introduced at the beginning of this chapter. If the arguments that are supposed to support the desire-based theory support the idea that only present desires provide reasons, and if the arguments that are supposed to support the value-based theory allow future desires to be involved in some way with reasons, then this suggests that Parfit is right. If not, then this suggests that Sobel is right.

I believe that an examination of these arguments shows that Parfit is right. Consider the arguments in support of the desire-based theory of reasons. According to the explanation argument, for something to be a normative reason, it must be at least potentially explanatory. It must be possible for it to be the reason (the motivating reason) the person did what he did. But mere future desires don't fit this bill. It could be that no matter what information a person was given (about smoking, say, and its effects on her future health and her future desires), and no matter how vividly it was presented, she could not be made to be motivated now to act so as to promote her future health and satisfy her future desires. She could not be made to care now about what she will care about in the future. Mere furure desires, therefore, can fail to be even potentially explanatory, and thus desire-based theorists who support their theory with considerations of explanatoriness are barred from claiming that they are reason-providing.

According to the motivation argument, a reason is, by nature, the sort of thing such that if a person has one, it cannot leave him cold, at least if presented to him in the right way. I said earlier that only the desire-based view can deliver this. But it would have been more accurate to say that only a desire-based view restricted to present desires can deliver this. If someone merely will have some desire in the distant future, there can be no guarantee that it won't leave him cold today.

According to the content argument, we should be skeptical of non-desirebased reasons because it is unclear what it could even mean to say that a person has one. By contrast, if a desire-based theory of reasons is true, it is always clear what it means to say that a person has a reason to do something. It means that if he deliberated soundly, he would want or be motivated to do it. But then desire-based theorists should be skeptical of reasons that are provided by future desires, since there need not be a sound deliberative toute from one's existing desires to one's future desires. The reasons future desires are alleged to be involved with should therefore be regarded by the internalist as belonging on the externalist side of the divide.

According to the reduction argument, the desire-based theory of reasons is preferable because, unlike the value-based theory, the desire-based theory allows for a plausible reduction of the normative, thereby avoiding a queer metaphysic and epistemology of irreducible normative facts. If a desirebased theory of reasons is true, the normative force that we feel we are responding to when we act on reasons can be reduced to the motivating force of the desires that motivate us to act when we act on reasons. But if the desire-based theory can appeal to future desires, this reduction will not work. There will be normative forces impinging on us now that are not reducible to the motivational forces impinging on us now, even if we have deliberated rationally. ${ }^{29}$

Finally, I'll note that independent of the fact that the main reasons for holding the desire-based view preclude an appeal to future desires, it does not seem to be in the spirit of the desire-based or internalist approach to reasons to appeal to desires that one merely will have, but whose objects one cannot be made to care about now. If there is a slogan for externalist theories of reasons, it is something like this: a person can have a reason to do something no matter what he cares about. When we say that the smoker has reasons to quit due to the future desire frustrations she will suffer, even though she cares nothing about this now, and couldn't be made to care, this sounds like externalism: she has a reason to quit no matter what she cares about.

One might object that desire-based theories already include future desires because, as we have noted, they include idealized desires, or desires the agent would have if the agent were to deliberate rationally. Since deliberating rationally takes at least some amount of time, these will be future desires. One point to make about this is that it is not clear that desire-based theories should appeal to the desires the agent would have if the agent were to take some time to deliberate rationally rather than the desires the agent would have now had, were the agent to have already deliberated rationally. Only the former view yields future desires. But even

\footnotetext{
29 It should be acknowledged that my points here do not apply to internalists, if there are any, who do not support their theory with any of these arguments.
} 
if the former view is acceptable, it still leaves out those future desires that are, as it were, out of deliberative reach - such as the future desires of Parfit's smoker above. In the case of matters of mere taste, when the valuebased theorist of reasons appeals to the future desires involved in the enjoyment of the chocolate ice cream to explain the present reasons it provides, it is no part of this explanation that these future desires are desires that the agent would have if he deliberated rationally. Thus, even if the desire-based theory isn't fully restricted to present desires, our explanation here of the reasons in cases of matters of mere tastc is a value-theoretic-rather than a desire-theoretic-friendly explanation. It falls on the value-based rather than the desire-based side.

\subsubsection{The Relevance of the Fact that Desire is Merely a Component of Enjoyment, the Reason-Providing State}

Another reason-i.e. in addition to the fact that future desires are futureit is legitimate for the value-based theorist to recognize that our future desires are involved in some of our reasons is that these desires are merely a component of the reason-providing state. The enjoyment that I will experience upon tasting the chocolate ice cream provides me with the reason to pick it. But on the desire-based theory of enjoyment, enjoyment is not desire. Enjoyment is a complex state consisting of an experience (or some other state), together with a desire for that experience (or state) to be going on. So what provides the reason to choose chocolate is the fact that, if I choose chocolate, I will be having an experience that I simultaneously desire to be having. Desire is one component of this; another component is the experience. Both must be among the effects of my choosing chocolate, along with the further fact that they occur at the same time, with the desire directed toward the experience, in order for me to have a reason to choose the chocolate. It is therefore not true that desires themselves are providing any reasons, or are the ultimate source of any reasons, even if it is true that one's reasons can vary depending upon one's (future) desires. Note also that the complex state that provides the reason here does so no matter our attitudes toward it. Although the state contains a pro-attitude as a component, it provides us reasons to act even if we have no pro-attitudes toward the prospect of being in such a state. This is something value-based, but not desire-based, theorists of reasons accept.

Consider an analogy. Suppose that W. D. Ross is correct that knowledge is intrinsically good for us. Suppose further that when something is intrinsically good for us, this gives us reason to bring it about. Thus, if I can do something that will help me acquire some knowledge, such as read some newspaper article, I will thereby have reason to do it. The reason to do this act will be provided by the fact that an effect of the act will be that I gain some knowledge. Now, a component of knowledge is truth: to know something is, in part, for that thing to be true. Should we therefore conclude that Ross is committed to the bizarre view that truth provides reasons-that is, to the view that if some act would lead to somerhing's being true, then that is a reason to perform the act? Of course not. What is providing the reason is the complex state of affairs of my knowing something. This state of affairs involves truth is reason-providing involves truth, but this by no means implies that true is that one's ress, or is the ultimate source of any reasons. All that is enjer when is the Likewise in the enjoyment case. What is providing the reason is the complex state of affairs of my experiencing some enjoyment. This state of affairs includes desire as a component, but this does not imply that that desire is reason-providing. ${ }^{30}$

One is reminded here of the Moorean doctrine of organic unities, the view that the intrinsic value of a whole may not equal the sum of the intrinsic values of its parts. This doctrine seems undeniable sumce we recognize that the items that are evaluatively basic - in that they are intrinsically valuable without having any parts that are intrinsically valuableneed not be metaphysically basic-in that they may have parts. This directly implies that there will be at least one, albeit rather trivial, kind of organic unity: the evaluatively basic things whose parts are of no value. Returning to the case of matters of mere taste, the picture the value-based theorist of reasons is envisioning is this: enjoyment is a "normatively basic" theorist of source of reasons, yet none of its parts is a source of reasons. In similar fashion, the hedonist will of its parts is a source of reasons. In similar intrinsically good, yet none of that enjoyment is evaluatively basic: it is intrinsically good, yet none of its parts is intrinsically good.

pleasure provides is important not only because it shows how it can be that pleasure provides reasons, that pleasure is to be explained in terms of desire, but desire doesn't provide reasons. It is important also because, if it were otherwise, the value-based theorist might run afoul of the arbitrariness

${ }^{30}$ A similar argument is made by Ruth Chang, who herself recects the value-based theory of teasons:

the dependence of some value based reasons on subjective states of the where this dependence is conceptual in natur on subjective states of the agent-even based view of reasons. One's having a desire for - does not itself undermine the valueactually existing, but no one would think for instance, conceptually depends on one's one's existence rather than one's desire. (Chang the "original source" of one's reasons is

pleasure provides reasons, it is "a complex of pleasure (2002: 339), and agrees that, when certain sensation while also desiring that his sential whole that involves, say, having a and not the desire by itself. 
argument. According to this argument, no reasons are based in a desire because, for this to happen, the desire could not be based in, or rationalized by, anything else (otherwise that something else would be basing the original reason). Thus, there is no reason to have the desire. But then this desire would be arbitrary. Since arbitrary states can't provide reasons, no reasons can be desire-based. Such reasons would be "built on sand."

But the reasons provided by enjoyment are not built on sand in this way. It is true that at least some of the desires that are involved in pleasure-e.g. our desires for certain taste sensations-cannot be intrinsically more and less reasonable. The desire to taste chocolate is not more reasonable (intrinsically) than the desire to taste vanilla. ${ }^{31}$ In this way, these preferences, too, are arbitrary. But since they are not providing the reasons on the value-based picture, this is ok. The reasons involved with enjoyment are not based on, in that they do not "bottom out" at, these arbitrary desires. They bottom out at a higher level, at the complex states consisting of one's having some experience one simultaneously desires to be having. This complex state is not arbitrary, for it, unlike the state of merely having a desire, is a good state to be in. It is thus plausible that this state, unlike an arbitrary desire, could provide us with reasons, despite the fact that the state contains, as a part, an arbitrary desire. ${ }^{32}$

Note that if we reject the buck-passing theory of value and accept instead the view that the property of goodness itself provides reasons, the point here is especially vivid. When desires and experiences come together in the right way in matters of mere taste, goodness arises. It is that this state would be a good state to be in that gives us reason to get ourselves in it, and not the constituent desire, or the constituent experience, or even the state of enjoyment they help make up. But even on the buck-passing view, the point stands. The reason-providing state is not any desire, but a state of enjoyment, which contains desire as a component.

31 An intrinsic reason to desire something is one that is not explained by the effects of having the desire but instead by the intrinsic nature of the object of the desire. It might be irrational to desire the smell of gasoline, but only because doing so will make one sick. This is an extrinsic reason. The smell of gasoline is not inherently or intrinsically This is an extrinsic
unworthy of desire.

32. Note that although the desires that are constituents of states of enjoyment are often arbitrary, our desires for enjoyment are not arbitrary. These are justified by the fact that enjoyment is itself a good state to be in.

\section{HOW ONE CAN BE A DESIRE-BASED THEORIST OF WELFARE AND A VALUE-BASED THEORIST OF REASONS}

Like all theories of welfare, desire-based theories of welfare purport to identify the things that are of ultimate benefit to us, the things that make our lives go well or badly for us. According to the desire-based theory of welfare, it is getting what we want, or desire satisfactions, that make our lives worth our while. ${ }^{33}$ The desire approach to welfare might be the most popular approach nowadays. ${ }^{34}$ One reason why is that it is believed that this approach best respects the idea that, when it comes to what is good for a person, the person herself has to be a kind of authority-not in an epistemic sense, in that she is best suited to know what is best for her (although this might also often be true), but constitutively, in that the person's particular predilections determine what is good for her. Some refer to this idea as an "internalism requirement" on welfare. Robert Noggle puts it thus:

The fact that desire-based theories make our well-being something that matters to us seems to be an advantage over theories that simply posit a list of things that make a person's life go well, whether they matter to the person or not... The reason that such internalism seems appropriate in a theory of well-being is that if we are measuring the extent to which a life is valuable for the person living it, then it seems that the criteria for evaluation must be those of the agent herself. The ends and goals in terms of which we exaluate the success of a person's life must not, it seems, be completely alien to the agent's own ends and goals. (Noggle 1999: 303)

The connection between this internalism about welfare and the internalism about reasons that we have been discussing should be obvious. It naturally leads one to think that being an internalist, or desire theorist, about welfare commits one to holding that at least some reasons are internal, or desirebased. But, as with the pleasure case, I believe that this is a mistake.

33 Advocates of a desire-based approach to welfare, of some form or other, include Brandt (1966), Rawls (1971: 92-3, 417), Overvold (1980, n. 10), Haslett (1990), Noggle (1999), Carson (2000), and myself (2006 and unpublished).

34 "Currently, the theory to beat is the desire theory of well-being, ... [ $[\mathrm{t}]$ he dominant account among economists and philosophers over the last century or so..." (Havbron 2008: 23). "Today the desire-satisfaction theory is probably the dominant view of welfare among economists, social-scientists, and philosophers, both utilitarian and non-utilitarian" (Shaw 1999: 53). "Desire theories have come to dominate the welfare landscape in this century in the way that hedonism dominated its own time" (Sumner 1996: 113). "Contemporary analyses of self-interest have usually identified it with some aspect of what the person wants" (Overvold 1982: 186) 
I believe it is a mistake because the most plausible forms of the desire theory of welfare will hold that the only desire satisfactions that are implicated in the reasons that a person has at a time are desire satisfactions that are future relative to that time. If they are, then the connections between normative reasons and present motivations that are required by desire-based theories of reasons-or at least required by the prominent arguments for desire-based theories of reasons - will be severed.

Whenever we act so as to satisfy some desire, it is plausible that this is good for us only when, when the thing we want comes about, we still want it, or still want that it came about. To deny this is to hold that we can be benefited by satisfying merely past desires. But this is implausible, as Richard Brandt, among others, has pointed out:

Suppose my six-year-old son has decided he would like to celebrate his fiftieth birthday by taking a roller-coaster ride. This desire now is hardly one we think we need attend to in planning to maximize his lifetime well-being. Notice that we pay no attention to our own past desires. (Brandt 1979: 249)

When the time comes to plan the fiftieth birthday party, we can ignore this past desire, assuming that it is indeed a merely past desire-i.e. that it is nor also had in the present and will not reappear in the future, especially on the day of the party, ${ }^{35}$

If it is of no benefit when merely past desires are satisfied, it follows that it is of no benefit to act so that our merely present desires are satisfied. For our acts can affect only the future. Once we have acted, to determine whether it was beneficial to perform that act, we shouldn't look at our desires at the time of the act for what our act might bring about, but instead at our desires after the act. For if we no longer desire what we get when we finally get it, nothing good has happened to us. Such a "desire satisfaction" is of no benefit, as Brandt's example above illustrates. And if they provide no benefit, they provide no reasons. Since the desire satisfactions that are caused by our acts are always future relative to those acts, no present desires or present desire satisfactions ever provide teasons to do anything. Future desire satisfactions do, but since there the requisite necessary connection to motivation is missing, this doesn't support the view that desires of the relevant sort-i.e. of the sort that are required for the prominent arguments for desire-based theories of reasons to work-ever provide reasons.

This is analogous to the pleasure case. The desire that is involved in the reason is a future desire. But desire-based theories of reasons, if they are

35 For similar views about the irrelevance of past desires, see Parfit (1984: 157) and Griffin (1986: 11): "[u] tility must, it seems, be tied at least to desires that are actual when satisfied." going to be supported by the main sorts of argument that have been given in support of them, cannot ground reasons in furure desires. These arguments require a necessary connection between one's reasons and one's motivations after ideal deliberation.

There is at least one complication: What about present desires concerning things past? Parfit writes,

I may want it to be true that, in my drunkenness last night, I did not disgrace myself. And I may want this to be true for its own sake, not because of its possible effects on my future. Similarly, after reading the letters of Keats or van Gogh, I may want it to be true that they knew how great their achievements were. (Parfit 1984: 171)

Brandt's case above involved a so-called then-for-now desire: a desire a person who is now turning fifty had when he was six concerning what would happen when he turned fifty. As we have seen, it is plausible that such desires have no bearing on one's welfare. Parfit's case involves a nowfor-then desire: a desire a person has now about what happened in the past. It is less clear what to say about such a case. Perhaps we should be more open to the thought that it is of benefit to satisfy such now-for-then desires. If this is right, then it isn't exactly correct that desire theorists of well-being should say that what's good is getting what one wants while one wants it. If Keats did know how great his achievements were and Parfit therefore gets what he wants, he is not getting what he wants while he wants it. What he wants is that Keats knew something; since Keats' and Parfit's lives never overlap, Parfit can't want this while it is obtaining. Parfit can get what he wants while he comes to believe it obtained, but this isn't the same thing.

But even if it is good for a person when a present desire about the past is satisfied, this doesn't undermine the claim that our present desires never provide reasons to act. This is because we cannot affect the past. There is no question of it turning out that Keats will have known how great he was if only Parfit does something now. Thus, the fact that Parfit presently wants Keats to bave known this will never be involved in any reasons for Parfit to do anything.

The futurity of the desires involved in the states that provide welfarerelated reasons is enough to sever the desire-based theory of welfare's commitment to internal reasons. But as with the pleasure case, this severance is overdetermined. For the fact that desires are merely a component of desire satisfactions is also enough to deliver this result. On desiresatisfaction theories of welfare, the things that are of ultimate benefit to us are desire satisfactions. These are complex states consisting of someone wanting something to occur or to be true, together with that thing's occurring, or being true. These complex states are the states that, when they are a part of our lives, make our lives better. The desires by themselves 
don't make our lives better; no desire theorist thinks that merely desiring things, irrespective of whether what is desired comes about, is any benefit on its own. And the events or propositions that can be the objects of our desires are similarly worthless to us on their own. What we need for things to be going well for us is both to be desiring some things and to be getting them.

Because it is only these complex states that contribute to our welfare, these are also the states that provide us with reason to bring them about-not any component of these states on its own. The item that is providing the reason is not a desire, but a state that contains a desire as a component. Thus, for this reason as well, desire-based theories of welfare are not committed to the view that desires themselves are ever an original source of reasons.

I am attracted to the desire-based theory of pleasure (Heathwood 2007a, $2007 \mathrm{~b}$ ) and also to a desire-based theory of welfare (Heathwood 2006, unpublished). I am also inclined to accept the value-based theory of reasons, which denies that desires are ever an original source of reasons This package of views can initially seem internally incoherent. I have here tried to explain why I believe that this is not so.

\section{References}

Brandt, Richard B. (1966) "The Concept of Welfare," in S. R. Krupp (ed.), The Structure of Economic Science (Englewood Cliffs, NJ: Prentice-Hall), 257-76.

- (1979) A Theory of the Good and the Right (Oxford: Clarendon Press).

Broad, C. D. (1959) Five Types of Ethical Theory (Paterson, NI: Littfield Adams).

Carson, Thomas L. (2000) Value and the Good Life (Norre Dame, IN: University of Notre Dame Press).

Chang, Ruth (2004) "Can Desires Provide Reasons for Action?," in R. J. Wallace (ed.), Reason and Value: Themes from the Moral Philosophy of Joseph Raz (Oxford Oxford University Press), 56 90.

Crisp, Roger (2006) Reasons and the Good (Oxford: Oxford University Press).

Dancy, Jonathan (2000) Practical Reality (New York: Oxford University Press).

Darwall, Stephen L. (1992) "Internalism and Agency," Philosophical Perspectives 6: $155-74$.

Dreier, James (1992) "The Supervenience Argument against Moral Realism," Southern Journal of Philosophy 30: 13-38.

Duncker, Karl (1941) "On Pleasure, Emotion, and Striving," Philosophy and Phenomenological Research 1: 391-430.

Feldman, Fred (1988) "Two Questions about Pleasure," in D. F. Austin (ed.), Philosophical Analysis (Norwell: Kluwer), 59-81.
(2001) "Hedonism," in L. C. Becker and C. B. Becker (eds.) The Encyclopedia of Ethics (New York: Routledge), 662-9.

- (2004) Pleasure and the Good Life: Concerning the Nature, Varieties, and Plausibility of Hedonism (Oxford: Clarendon Press).

Goldman, Alan H. (2006) "Desire Based Reasons and Reasons for Desires," Southern Journal of Philosophy 44: 469-88.

Griffin, James (1986) Well-Being (Oxford: Clarendon Press).

Hall, Richard J. (1989) "Are Pains Necessarily Unpleasant?" Philosophy and Phenomenological Research 49: 643-59.

Harman, Gilbert (1977) The Nature of Morality (New York: Oxford University Press).

Haslett, D. W. (1990) "What Is Utility?" Economics and Philosophy 6: 65-94.

Haybron, Daniel M. (2008) "Philosophy and the Science of Subjective WellBeing," in M. Eid and R. J. Larsen (eds.), The Science of Subjective Well-Being (New York: Guilford Press), 17-43.

Heathwood, Chris (2006) "Desire Satisfactionism and Hedonism," Philosophical Studies 128: 539-63.

- (2007a) "The Reduction of Sensory Pleasure to Desire," Philosophical Studies 133: $23-44$

- (2007b) "Review of Roger Crisp, Reasons and the Good" Notre Dame Philosophical Revieus.

- (unpublished) "Subjective Desire Satisfactionism."

Huemer, Michael (2005) Ethical Intuitionism (Basingstoke: Palgrave Macmillan).

Kagan, Shelly (1992) "The Limits of Well-Being," Social Philosophy and Policy 9: $169-89$.

Korsgaard, Christine M. (1986) "Skepticism about Practical Reason," Journal of Philosophy 83: 5-25.

Mackie, J. L. (1977) Ethics: Inventing Right and Wrong (New York: Penguin).

McDowell, John (1998) "Might There Be External Reasons?" in Anonymous, Mind, Value, and Reality (Cambridge, MA: Harvard University Press), 95-111.

Moore, G. E. (1903) Principia Ethica (Cambridge: Cambridge University Press).

Noggle, Robert (1999) "Integrity, the Self, and Desire-Based Accounts of the Good," Philosophical Studies 96: 303-31.

Overvold, Mark Carl (1980) "Self-Interest and the Concept of Self-Sacrifice," Canadian Journal of Philosophy 10: 105-18.

- (1982) "Self-Interest and Getting What You Want," in H. B. Miller and W. H. Williams (eds.), The Limits of Utilitarianism (Minneapolis: University of Minnesota Press), 18694.

Parfit, Derek (1984) Reasons and Persons (Oxford: Clarendon Press).

- (1997) "Reasons and Motivation," Proceedings of the Aristotelian Society, Supplementary Volumes 71 (1997): 99-130.

- (2001) "Rationality and Reasons," in D. Egonsson, J. Josefsson, B. Peterson, and T. Rønnow-Rasmussen (eds.), Exploring Practical Philosophy: From Action to Values (Aldershot: Ashgate Publishing), 17-39. 
Parfit, Derek (2006) "Normativity," in R. Shafer-Landau (ed.), Oxford Studies in Metaethics, i, (Oxford: Clarendon Press), 325-80.

- (forthcoming) On What Matters (Oxford: Oxford University Press).

Phillips, David (2007) "Mackie on Practical Reason," Ethical Theory and Moral Practice 10: 457-68.

Quinn, Warren (1993) "Putting Rationality in its Place," in Morality and Action (Cambridge: Cambridge University Press), 228-55.

Railton, Peter (1999) "Normative Force and Normative Freedom: Hume and Kant, but not Hume Versus Kant," Ratio 12: 320-53.

Rawls, John (1971) A Theory of Justice (Cambridge, MA: Belknap Press).

Raz, Joseph (1999) "Incommensurability and Agency," in Engaging Reason: On the Theory of Value and Action (New York: Oxford University Press), 46-67.

Scanlon, T. M. (1998) What We Owe to Each Other (Cambridge, MA: Belknap Press).

- (2002) "Replies," Social Theory and Practice 28: 337-58.

Schroeder, Mark (2007) Slaves of the Passions (Oxford: Oxford University Press).

Shafer-Landau, Russ (2003) Moral Realism: A Defence (Oxford: Clarendon Press).

Shaw, William H. (1999) Contemporary Ethics: Taking Account of Utilitarianism (Malden, MA: Blackwell).

Sidgwick, Henry (1907) The Methods of Ethics (London: Macmillan and Co.).

Smith, Michael (1994) The Moral Problem (Oxford: Blackwell).

Smuts, Aaron (forthcoming) "The Feels Good Theory of Pleasure," Philosophical Studies.

Sobel, David (2005) "Pain for Objectivists: The Case of Matters of Mere Taste," Ethical Theory and Moral Practice 8: 437-57.

Spencer, Herbert (1871) The Principles of Psychology (New York: D. Appleton and Company).

Sumner, L. W. (1996) Welfare, Happiness, and Ethics (Oxford: Clarendon Press).

Williams, Bernatd (1981) "Internal and External Reasons," in Moral Luck (Cambridge: Cambridge Universiry Press), 101-13. 